\title{
The Fish Fauna of Göynük Stream (Bingöl)
}

\author{
Mustafa KOYUN ${ }^{1 *}$, Bülent GÜL ${ }^{1}$, Nimetullah KORKUT1 ${ }^{1}$
}

${ }^{1}$ Zoology Section, Department of Biology, Faculty of Arts and Sciences, Bingöl University, Bingöl, Turkey

\begin{abstract}
Received: 08.03 .2018
Accepted: 03.05.2018

Available online: 04.06 .2018

Published: 30.06 .2018

Abstract: This study was carried out between May 2013 and December 2015 in the Göynük Stream (Bingöl) that is one of the most important tributaries of the Murat River. Considering the stream tributaries connected to the Göynük Stream, the samples were captured from five stations: Garip Village, Ilıcalar Creek, Derinçay, Taşliçay and Kale. In this study, 1349 fish samples were recorded in a total of 21 taxa including 14 taxa belonging to Cyprinidae, 3 to Nemacheilidae, 1 to Cobitidae, 2 to Sisoridae, and 1 to Mastacembelidae. Therefore, Cyprinidae was the predominant family. 1057 (78\%) samples from the 14 taxa of Cyprinidae and 292 (22\%) samples from the remaining 7 taxa of other 4 families were reported at the end of the study. The most dominant species in this study were: Capoeta umbla, Capoeta trutta, and Squalius semae from Cyprinidae family. Garra rufa and Cyprinion macrostomum species, which are endemic to the Euphrates and Tigris basin and have an important place in the freshwater fish literature in the world, were particularly abundant in Ilıcalar Creek, a section of the Göynük Stream. The aim of this study was to determine the fish fauna of the Göynük Stream on which there are five irrigation pump stations and HES reservoirs.
\end{abstract}

Keywords: Göynük Stream, Ichthyo fauna, Teleostei, Turkey

\section{Göynük Çayı (Bingöl) Balık Faunası}

Özet: Bu çalışma, Murat Nehri'ni besleyen en önemli kollardan biri olan Göynük Çayı'nda, Mayıs 2013 ve Aralık 2015 tarihleri arasında gerçekleştirilmiştir. Göynük Çayı'na bağlanan dere kolları da dikkate alınarak, örnekler Garip Köyü, Ilıcalar deresi, Derinçay, Taşlıçay ve Kale olmak üzere beş istasyondan yakalanmıştır. Çalı̧̧ma boyunca toplam 21 taksonda 1349 balık örneği kaydedilmiştir. Bu 21 taksonun, 14'ü Cyprinidae, 3'ü Nemacheilidae, 1'i Cobitidae, 2'si Sisoridae ve 1'i de Mastacembelidae familyalarına ait olduğu tespit edilmiştir. Çalışma sonunda, Cyprinidae'den 14 taksona ait 1057 (\%78), diğer 4 familyaya ait 7 taksonda ise $292(\% 22)$ adet ve oranda örnek yakalanmıştır. Bu çalışmada öne çıkan baskın türlerin Cyprinidae'den Capoeta umbla, Capoeta trutta ve Squalius semae olduğu görülmüştür. Fırat ve Dicle nehir sisteminde rastlanan ve dünya tatlısu balık literatüründe önemli yeri olan Garra rufa ve Cyprinion macrostomum türlerinin özellikle Göynük Çayı'nı besleyen Ilıcalar Deresi ve buna yakın kesimlerde popülasyonca daha fazla olduğu kaydedilmiştir. Bu çalışma, üzerinde beş adet sulama ve HES barajı bulunan Göynük Çayı'nın balık faunasını tespit etmek amacıyla yapılmıştır.

Anahtar kelimeler: Göynük Çayı, Balık faunası, Teleostei, Türkiye

\section{Giriş}

Türkiye'de tatlısu balık faunası alanında çalışmalar, 1835 yilında Abbolt tarafından Trabzon'un tatlısu kaynaklarından topladığı alabalıklar (Salmonidae)'la ilgili yaptığı çalışmalarla başlamıştır (Geldiay \& Balık, 2007). Türkiye'nin tatlısu balıklarıyla ilgili 1940 'lardan bugüne kadar gerek yerli ve gerekse yabancı araştırmacılar tarafından yapılmış birçok sistematik çalışma bulunmaktadır (Kuru, 1971; 1975; 1980; 2004, Çoban et al., 2013; Kuru et al., 2014). Farklı su kaynaklarında bulunan balıkların biyolojik özelliklerinin metrik ve meristik özelliklerinin belirlenmesi balık faunası için önemlidir (Vatandoust et al., 2014).

Bu çalışmanın yürütüldüğü Göynük Çayı; Bingöl Dağları, Kargapazarı Köyü sinırlarından doğup, Karlıova'nın Güneydoğusunda Kale Köyünden, Batısında Kaynak Köyü civarından ve Taşlıçay Köyünden çıkan üç koldan membainı almaktadır. Taşlıçay'dan gelen kol ile Kale'den gelen kol Boncukgöze Köyü civarında birleşirler (Şekil 1). Kaynak Köyü tarafından gelen çay, Aşağı Derinçay ile Yeniköy arasında, Göynük Çayı'yla birleşir. Ilıcalar Deresi de Göynük Çayı'nı besleyen önemli kollardandır. Göynük Çayı, Gayd Deresi ile birleştikten sonra Murat Nehri'ne ulaşır. Göynük Çayı üzerinde tamamlanmış ve inşa halinde küçük ölçekli 5 adet HES, sulama amaçlı 2 baraj bulunmaktadır (Enerji atlası). Barajların yapımı sonucu akarsu ekosisteminin flora ve faunasında büyük değişimler meydana gelmiştir (Günek, 2006). Barajların inşa aşamasında ve sonrasında doğal su yataklarının akış güzergâhlarında kısmi veya sürekli değişmelerin olması habitat bozulmalarına sebep olmaktadır. Barajların yapılması ile akarsu rejiminin değişmesi, akarsu yatağında daha az suyun olması, öncelikle balıklar olmak üzere besin zincirine bağlı olarak suda yaşayan birçok sucul canlının üreyip çoğalmasını olumsuz yönde etkilemektedir (Sönmez, 2012; Aşık, 2016). Bu ve benzer nedenlerden dolayı, sucul ortamdaki biyolojik çeşitlilik büyük zarar görmektedir. Hatta bazı sucul türlerin ilerleyen zamanlarda yok olma tehlikesi yüksektir.

Göynük Çayı'nın Murat Nehri'ne, Murat Nehri'nin de Fırat - Dicle nehir sistemi ile bağlantılı olması nedeniyle bu akarsularda balık faunasına yönelik yapılan çalışmalar (Birecikligil \& Çiçek, 2010; Yıldırım et al., 2015; Kaya et al., 2016) göz önünde bulundurulurmuştur. Göynük Çayı'nın balık faunası ile ilgili herhangi bir çalışma bulunmadığından, çeşitli sebeplerden dolayı (yaşam alanlarının tahribi, dere yataklarındaki değişimler, aşırı avcılık vs.) ilerleyen 
yıllarda balık faunasında değişimler olabileceği varsayımıyla bu çalışma yapılmıştır.

\section{Materyal ve Metot}

$\mathrm{Bu}$ araştırma, Doğu Anadolu'nun önemli su kaynaklarından Murat Nehri'nin kollarından biri olan Göynük Çayı'nda gerçekleştirilmiştir. Arazi çalışmaları, Mayıs 2013 ve Aralık 2015 tarihleri arasında yapılmıştır. Balık örnekleri, Garip Köyü, Ilıcalar deresi, Derinçay, Taşlıçay ve Kale olmak üzere beş istasyondan yakalanmıştır (Şekil 1, Tablo 1). Çalışma boyunca söz konusu istasyonlarından toplam 21 taksonda 1349 adet balık yakalanmıştır. Yakalanan balıklar içerisinde \% 4 lük formaldehit bulunan plastik kaplarda tespit edilerek laboratuvara getirilmiş olup, çalışmalar bu örnekler üzerinden yürütülmüştür (Tablo 2).
Örneklerin fotoğrafları çekilmiş ve metrik özellikler mm hassasiyette dijital kumpas ve cetvel ile ölçülmüştür. Balıklarda standart boy (SB), vücut yüksekliği (VY), baş boyu (BB), göz çapı (GÇ) ve interorbital uzunluk (İU) ölçümleri yapılmıştır. Meristik özelliklerden, dorsal yüzgeç (D), anal yüzgeç (A), pektoral yüzgeç $(\mathrm{P})$, ventral yüzgeç $(\mathrm{V})$ ışın sayıları, ligne lateral pul sayısı (L. lat.) ligne transversal pul sıra sayıları (L. trans.), ve solungaç dikenleri sayısı (Sol. dik.) tespit edilmiştir. Araştırma alanından yakalanan balıkların tür tayinleri örneklerin morfometrik ve meristik özellikleri dikkate alınarak (Lagler et al., 1977; Scott. \& Crossman, 1979; Geldiay \& Balık, 2007; Ekingen \& Erbucan, 1993; Erk'akan et al., 1999; Kuru, 2004; Fishbase, 2018; Kaya et al., 2016)'dan yararlanilarak familya, cins ve tür düzeyinde belirlenmiştir.

Tablo 1. Örneklerin istasyonlarına ait GPS koordinatları

\begin{tabular}{|c|c|c|c|c|c|}
\hline \multirow{2}{*}{$\begin{array}{l}\text { İstasyonlar } \\
\text { Garip Köyü }\end{array}$} & \multicolumn{2}{|c|}{ Öncül koordinatlar } & \multicolumn{2}{|c|}{ İkincil koordinatlar } & \multirow{2}{*}{$\frac{\text { Rakım }}{1080}$} \\
\hline & $4307467-\mathrm{K}$ & (37S)0629336-D & 38.90500-K & 40.49137-D & \\
\hline Ilıcalar Dersi & $4316836-\mathrm{K}$ & (37S)0645210-D & 38.98692-K & 40.67635-D & 1200 \\
\hline Derinçay & 4333474-K & (37S)0660535-D & 39.13409-K & 40.85713-D & 1644 \\
\hline Taşlıçay Köyü & 4347979-K & (37S)0671593-D & 39.26261-K & 40.98868-D & 1787 \\
\hline Kale Köyü & 4345922-K & (37S)0673088-D & $39.24379-\mathrm{K}$ & 41.00547-D & 1760 \\
\hline
\end{tabular}

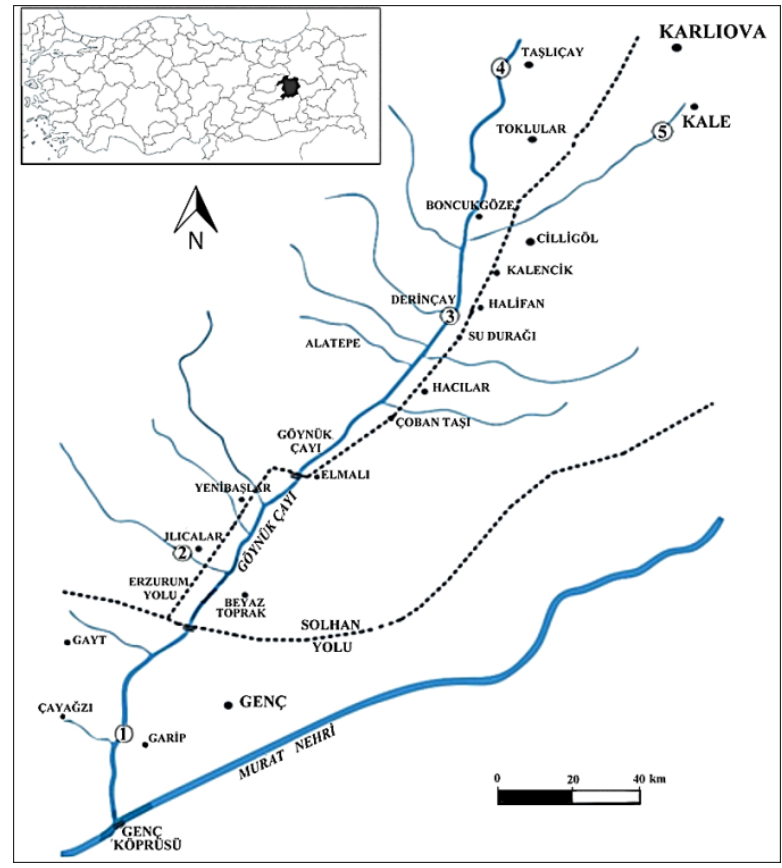

Şekil 1. Çalışma alanı Göynük Çayı (Bingöl) haritası ve istasyonlar (1. Garip Köyü; 2. Ilıcalar; 3. Derinçay; 4. Taşlıçay; 5. Kale)

\section{Bulgular}

Mayıs 2013-Aralık 2015 tarihleri arasında Göynük Çayı'ndan çeşitli av araç ve gereçleri (olta, çeşitli büyüklüklerdeki kepçeler, farklı göz açıklığına sahip germe ve serpme ağları) ile 5 farklı istasyondan örnekleme yapılmış, 5 familya bir alt familya ve 15 cinse ait 21 balık türü kaydedilmiştir. Bu 21 taksonun, 14'ü Cyprinidae'ye olduğu, ancak Snout et al. (2016)'ya göre bunlardan 5 bıyıksız türün ağı ve çevresinde bıyık ve benzeri yapıların olmaması özelliklerine göre (Squalius semae, Acanthobrama marmid, Chondrostoma regium, Alburnus sellal ve Alburnoides bipunctatus) Leuciscinae alt familyasına ait olduğu anlaşılmaktadır. Diğer taksonlardan 3'ü Nemacheilidae, 1'i Cobitidae, 2'si Sisoridae ve 1'inin de Mastacembelidae familyasına ait olduğu tespit edilmiştir. Elde edilen örneklerden Cyprinidae familyasinin 14 taksonunda toplamda 1057 balık örneği (\%78), bu miktarın 394 örneği Leuciscinae alt familyasına ait olduğu bildirilirken diğer 4 familyaya ait 7 taksondan 292 (\%22) örnek temin edilebilmiştir (Şekil 3). Özellikle Leuciscinae alt familyasına ait $S$. semae ve $A$. sellal türlerinin fauna içinde baskın popülasyonlarının olduğu görülmektedir.

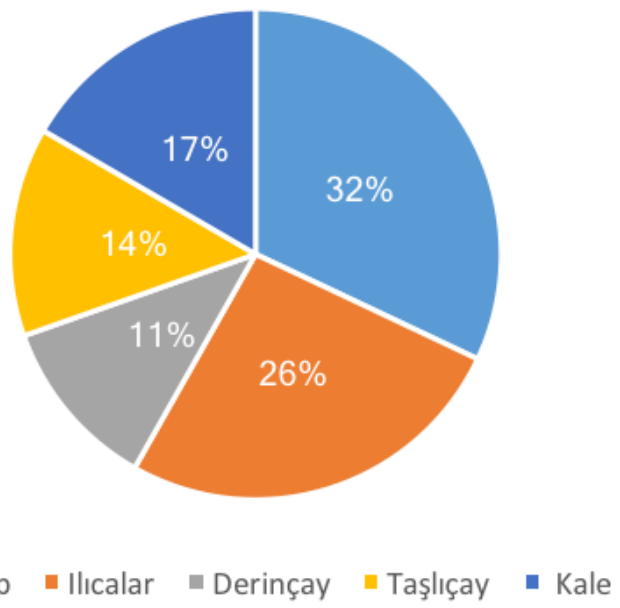

Şekil 2. Kaydedilen familyaların istasyonlara göre dağglım oranları 
Tablo 2. Çalışmada kaydedilen balıkların sayısal dağılımları

\begin{tabular}{|c|c|c|c|c|c|}
\hline Familya & Balık türü & $\begin{array}{c}\text { Yakalanan } \\
\text { balık Sayısı }\end{array}$ & $\begin{array}{c}\text { İstasyondaki } \\
\% \text { oranı }\end{array}$ & $\begin{array}{c}\text { Totaldeki } \% \\
\text { oranı }\end{array}$ & $\begin{array}{c}\text { Yakalandı̆ } \\
\text { İstasyon }\end{array}$ \\
\hline \multirow{9}{*}{ Cyprinidae } & Capoeta umbla & 218 & 50 & 16 & $1 ; 2 ; 3 ; 4 ; 5$ \\
\hline & Capoeta trutta & 125 & 29 & 9 & $1 ; 2 ; 3 ; 4 ; 5$ \\
\hline & Cyprinus carpio & 3 & 0,7 & 0,02 & 1 \\
\hline & Cyprinion macrostomum & 90 & 21 & 7 & $1 ; 2$ \\
\hline & Barbus lacerta & 85 & 20 & 6 & $1 ; 2 ; 3 ; 4 ; 5$ \\
\hline & Arabibarbus grypus & 40 & 9,2 & 3 & 1 \\
\hline & Luciobarbus xanthopterus & 3 & 0,7 & 0,02 & 1 \\
\hline & Luciobarbus esocinus & 5 & 1,1 & 0,04 & 3 \\
\hline & Garra rufa & 94 & 22 & 7 & $1 ; 2 ; 3 ; 4 ; 5$ \\
\hline \multirow{5}{*}{ Leuciscinae } & Squalius semae & 116 & 27 & 9 & $1 ; 2 ; 3 ; 4 ; 5$ \\
\hline & Acanthobrama marmid & 39 & 9 & 3 & $1 ; 2 ; 3 ; 4 ; 5$ \\
\hline & Chondrostoma regium & 26 & 6 & 2 & 1 \\
\hline & Alburnus sellal & 135 & 31 & 10 & $1 ; 2 ; 3 ; 4 ; 5$ \\
\hline & Alburnoides bipunctatus & 78 & 18 & 6 & $2 ; 3 ; 4 ; 5$ \\
\hline \multirow{3}{*}{ Nemacheilidae } & Oxynoemacheilus angorae & 64 & 15 & 5 & $1 ; 2 ; 4$ \\
\hline & Oxynoemacheilus bergianus & 31 & 7 & 2 & $1 ; 2$ \\
\hline & Oxynoemacheilus tigris & 57 & 13 & 4 & $1 ; 2 ; 4$ \\
\hline Cobitidae & Cobitis elazigensis & 38 & 9 & 3 & $1 ; 2$ \\
\hline \multirow[b]{2}{*}{ Sisoridae } & Glyptothorax armaniacus & 45 & 10 & 3 & $1 ; 3 ; 4$ \\
\hline & Glyptothorax kurdistanicus & 37 & 8,5 & 3 & $1 ; 3 ; 4$ \\
\hline Mastacembelidae & Mastacembalus mastacembalus & 20 & 5 & 1,5 & 1 \\
\hline Total & & 1349 & - & - & \\
\hline
\end{tabular}

Not: Çalışma istasyonları ve yakalanan toplam balık sayıları; 1. Garip Köyü (432); 2. Ilıcalar (353); 3. Derinçay (154); 4 . Taşlıçay (186); 5. Kale (224)
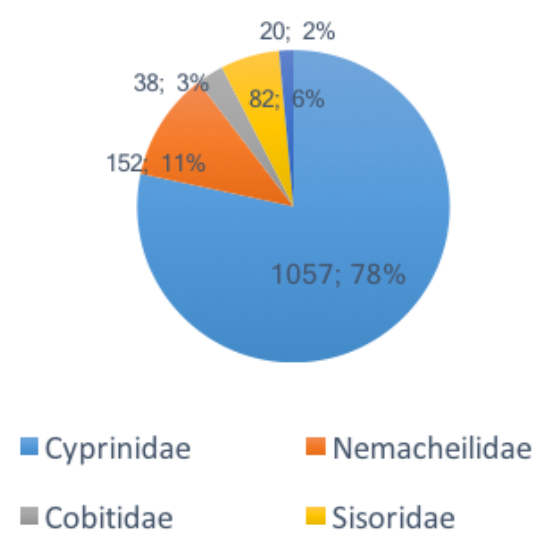

Mastacembelidae

Şekil 3. Kaydedilen taksonların familyalara göre dağılım oranlar1
Capoeta umbla (Heckel, 1843)

Türkçe Adı: Siraz balığ 1

İngilizce Adı: Tigris scraper

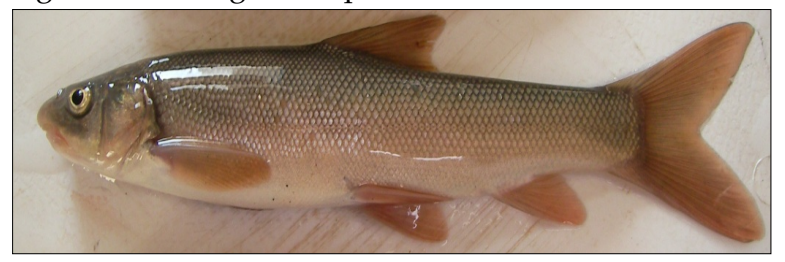

Şekil 4. Capoeta umbla (Heckel, 1843)

SB: 118,4 (83-159); SB/VY: 4,1 (4,0-4,3); SB/BB: 4,9 (4,7- 5,3); BB/GÇ: 6,1 (5,0-6,7); BB/İU: 1,9 (1,8-2,1); IUU/GÇ: 3,1 (2,3-3,6); D: II-III 8; A: II 6; P: I 13; L. lat.:7595; Sol. dik.: 18-22. Bu tür; 1, 2, 3, 4 ve 5 no'lu istasyonlardan yakalanmıştır. 
Capoeta trutta (Heckel, 1843)

Türkçe Adı: Karabalık

İngilizce Adr: Longspine scraper

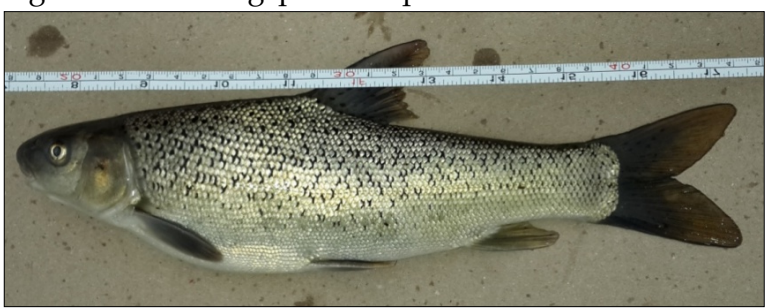

Şekil 5. Capoeta trutta (Heckel, 1843)

SB: 136 (135-137); SB/VY:3,6 (3,5-3,8); SB/BB:5,1 $(5,0-5,2) ; \quad$ BB/GÇ:7,3 (7,1-7,5); BB/İU:3,8 (3,8-3,9); İU/GÇ:1,9 (1,8-1,98); D: II-III/8-9; A: I-III/5-9; P: I-II/914; V: I/7-8; L. lat.: 77-93; Sol. dik.: 18-22. Bu tür; 1, 2, 3, 4 ve 5 no'lu istasyonlardan yakalanmıştır.

\section{Cyprinus carpio (Linnaeus, 1758)}

Türkçe Adı: Aynalı sazan, Pullu sazan

İngilizce Adı: Common carp, Mirror carp

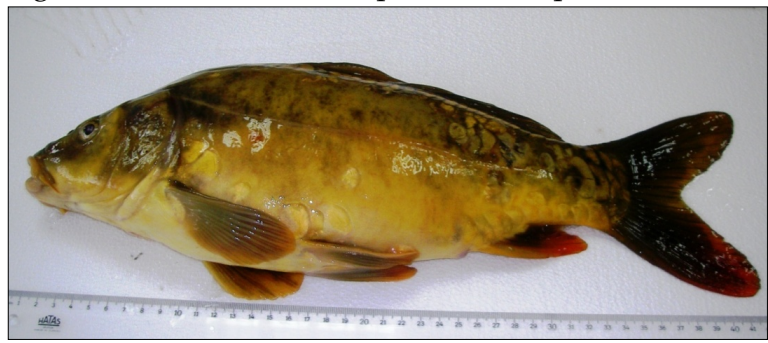

Şekil 6. Cyprinus carpio (Linnaeus, 1758)

SB: 246,1 (149-337); SB/VY: 2,7 (2.5-2.5); SB/BB: 4,2 (3,6-4,4); BB/GÇ:6,3 (4,1-6,3); BB/IUU: 2,3 (2,1-2,3); IUU/GÇ:2,6 (1,7-2,9); D: III/18-20; A: III/4-6; P: II/11-15; V: II/7-8; L. lat.: 23-38; L. trans.: 7-8; Sol. dik.: 23-30. Bu tür sadece1 no'lu istasyondan yakalanmıştır.

\section{Cyprinion macrostomum Heckel, 1843}

Türkçe Adı: Beni balığı

İngilizce Adı: Tigris kingfish

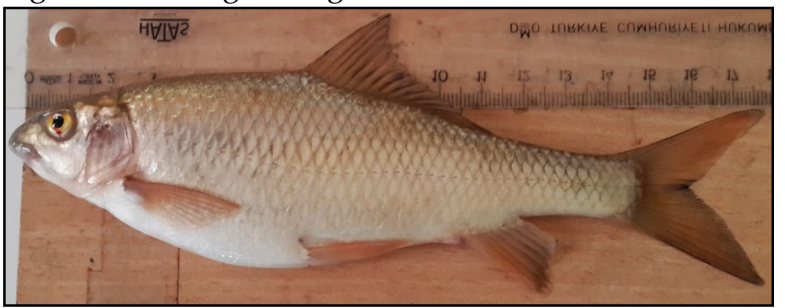

Şekil 7. Cyprinion macrostomum Heckel, 1843

SB: 99,2 (77-127); SB / VY: 2,9 (2,8-3,5); SB/BB: 4,7 $(4,6-4,8) ; \quad$ BB/GÇ:3,9 (3,3-4,5); BB/İU:2,3 (2,1-2,5); IUU/GC:1,6 (1,5-1,8); D: IV/14-16; A: III/7; P: I/11-12; V: I/8; L. lat.: 35-43; L. trans.: 7-8/3-5; Sol. dik.: 37-40. Bu tür; 1 ve 2 no'lu istasyonlardan yakalanmıştır.

\section{Barbus lacerta Heckel, 1843}

Türkçe Adı: Bıyıklı balık

İngilizce Adı: Lizard barbel

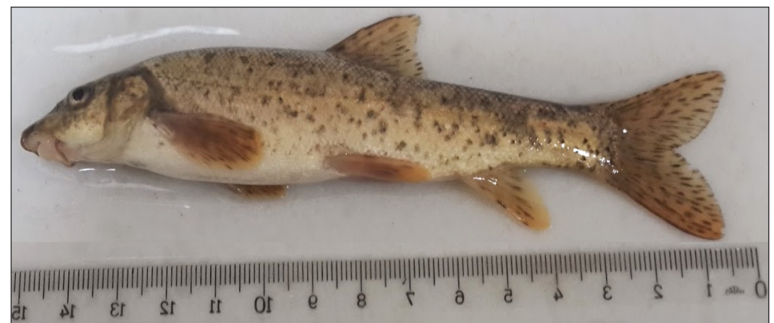

Şekil 8. Barbus lacerta Heckel, 1843

SB: 119,8 (77-155); SB/VY: 4,1 (4-4,2); SB/BB: 4,5 $(4,1-4,5) ; \quad$ BB/GÇ:6,0 (5,7-6,4); BB/İU:2,2 (2,0-2,8); IU/GÇ:2,7 (2,0-3,1); D: II/8; A: II/5; P: I/13; V: I/7-8; L. lat.: 56-77; L. trans.: 10-13/7-10; Sol. dik.: 12-15. Bu tür; 1 , 2, 3, 4 ve 5 no'lu istasyonlardan yakalanmıştır.

Arabibarbus grypus (Heckel, 1843)

Türkçe Adı: Bıyıklı balık, Şabut

İngilizce Adı: Shabout

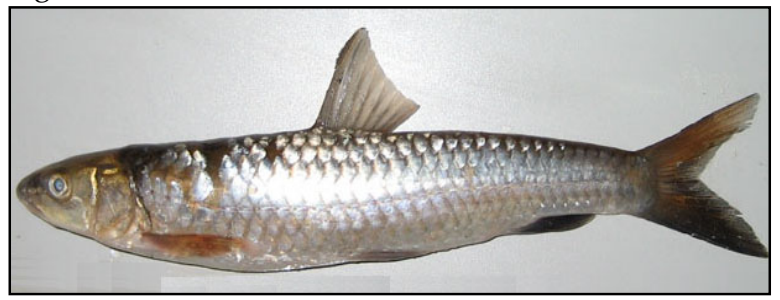

Şekil 9. Arabibarbus grypus (Heckel, 1843)

SB: 201,5 (185-212); SB/VY: 5,2 (4,9-5,0); SB/BB: 5,0 (4,9-5,1); BB/GÇ:4,8 (4,0-5,9); BB/İU:2,4 (2,2-2,5); İU/GÇ:2,1 (1,6-2,4); D: III/8; A: III/6; P: I/13; V: II/8; L. lat.: 41; L. trans.: 5-4/4-3; Sol. dik.: 22-25. Bu tür sadece 1 no'lu istasyondan yakalanmıştır.

\section{Luciobarbus xanthopterus Heckel, 1843}

Türkçe Adı: Maya balığı

İngilizce Ad1: Gattan

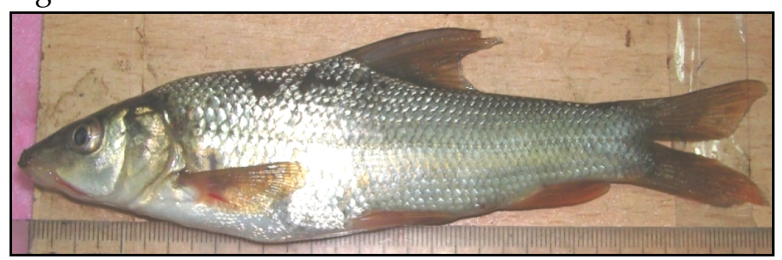

Şekil 10. Luciobarbus xanthopterus Heckel, 1843

SB: 242,5 (148-411); SB/VY: 3,8 (3,3-4,2); SB/BB: 4,0 (4,1-4,5); BB/GÇ:6,4 (4,6-8,0); BB/İU:2,9 (2,4-3,0); İU/GC: 2,2 (1,8-2,6); D: IV/8-9; A: III/6; P: I/15-16; V: I/7-8; L. lat.: 55-60; L. trans.: 10/7-9; Sol. dik.:12-14. Bu tür sadece 1 no'lu istasyondan yakalanmıştır.

\section{Luciobarbus esocinus Heckel, 1843}

Türkçe Adı: Cero manyar, mangar İngilizce Adı: Pike barbel

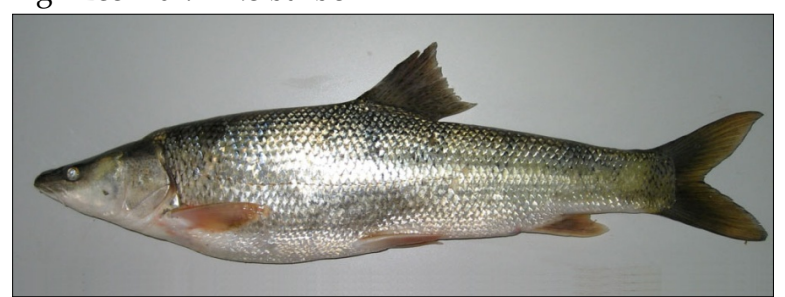

Sekil 11. Luciobarbus esocinus Heckel, 1843 
SB: 342 (242-481); SB/VY: 3,8 (3,7-4,2); SB/BB: 4,0 $(3,6-4,5) ; \quad$ BB/GÇ:8,6 (8,1-8,7); BB/İU:3,1 (3,0-3,4); İU/GÇ:2,7 (2,5-2,8); D: IV/9; A: III/6; P: I/16; V: I/8; L. lat.: 61-72; L. trans.: 11-12/7-9; Sol. dik.: 13-21. Bu tür sadece 3 no'lu istasyondan yakalanmıştır.

\section{Garra rufa (Heckel, 1843)}

Türkçe Adı: Yağlı balık, Kaya balığı, Vantuzlu balık İngilizce Adı: Doctor fish

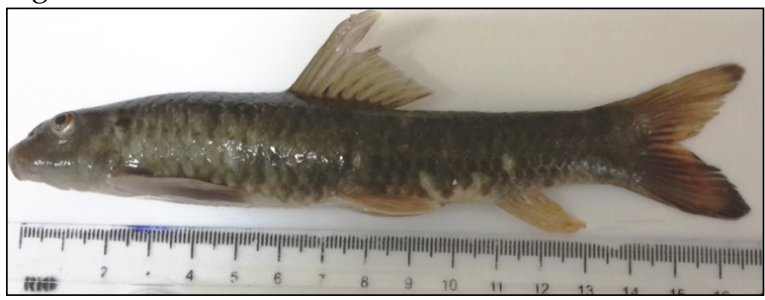

Şekil 12. Garra rufa (Heckel, 1843)

SB: 93,5 (55-117); SB/VY: 4,2 (3,5-4,4); SB/BB: 3,9 (3,3-4,1); BB/GÇ:6,5 (5,8-6,8); BB/İU:5,2 (4,9-5,3); İU/GÇ:1,2 (1,1-1,3); D: III/7-8; A: II/4; P: I/12; V: I/8; L. lat.: 34-39; L. trans.: 4-5/3-4; Sol. dik.: 12-22. Bu tür; 1 , 2, 3, 4 ve 5 no'lu istasyonlardan yakalanmıştır.

\section{Leuciscinae}

Squalius semae (Linneus 1758)

Türkçe Adı: Tatlısu kefali

İngilizce Adı: Chub

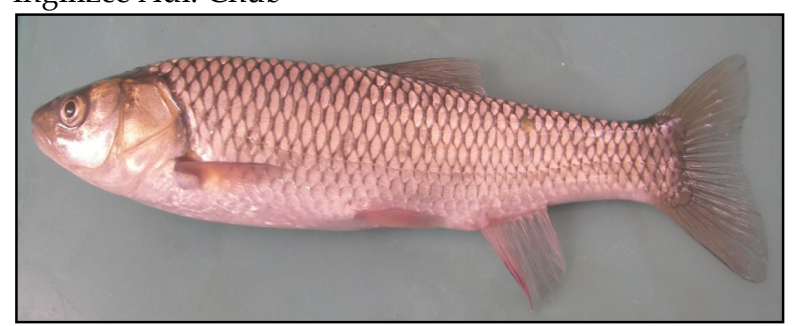

Şekil 13. Squalius semae (Linneus 1758)

SB: 122 (105-152); SB/VY: 3,6 (3,5-4,6); SB/BB: 4,2 (4,2-4.6); BB/GC:5,8 (4,6-6,9); BB/İU:2,1 (2,0-2,1); İU/GÇ:2,7 (2,2-3,4); D: III/8; A: III/9; P: I/13; V: I-II/8; L. lat.: 43-48; L. trans.: 8/4; Sol. dik.: 11-16. Bu tür; 1, 2, 3,4 ve 5 no'lu istasyonlardan yakalanmıştır.

\section{Acanthobrama marmid Heckel, 1843}

Türkçe Adı: Akçapak balığı

İngilizce Adı: Mesopotamian bream

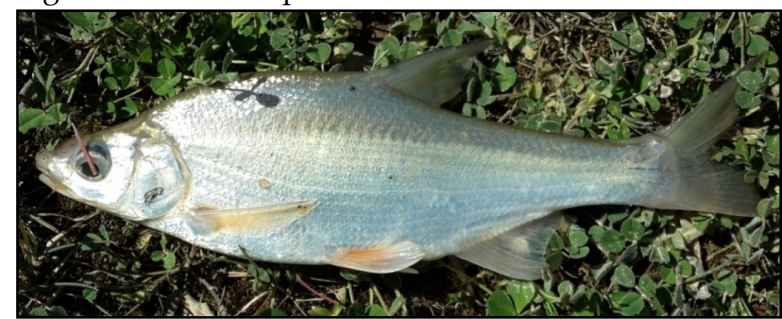

Şekil 14. Acanthobrama marmid Heckel, 1843

SB: 133 (128-140); SB/VY: 3,3 (3,3-3,4); SB/BB: 4,6 $(4,3-5,0) ; \quad$ BB/GÇ:3,6 (3,6-3,7); BB/İU: $1,0 \quad(0,8-1,1)$; İU/GÇ: 1,3 (1,3-1,4); D: II-III/8-9; A: III/15-16; P: I/914;V: II/9; L. lat.: 56-78; L. trans.: 13-21/7-9; Sol. dik.: 12-18. Bu tür; 1, 2, 3, 4 ve 5 no'lu istasyonlardan yakalanmıştır.
Chondrostoma regium (Heckel, 1843)

Türkçe Adı: Kababurun balığı

İngilizce Adı: Brond snout

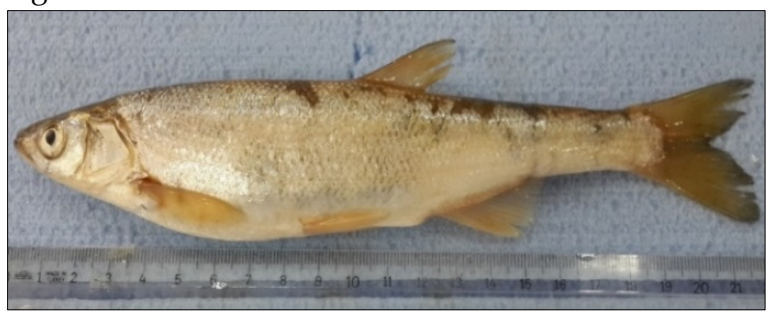

Şekil 15. Chondrostoma regium (Heckel, 1843)

SB: 109,3 (83-136); SB/VY: 4,3 (4,1-4,4); SB/BB: 4,8 $(4,4-5,2) ; \quad$ BB/GÇ:4,4 (4,1-4,4); BB/İU:2,5 (2,4-2,5); İU/GÇ:1,7 (1,6-1,8); D: III/8; A: III/10-11; P: I/13-15; V: I-II/7- 8; L. lat.: 65-72; L. trans.: 10-12/6; Sol. dik.: 24-29. Bu tür; 1 ve 3 no'lu istasyonlardan yakalanmıştır.

\section{Alburnus sellal Heckel, 1843}

Türkçe Adı: Tatlısu gümüş balığı

İngilizce Adı: Sellal bleak

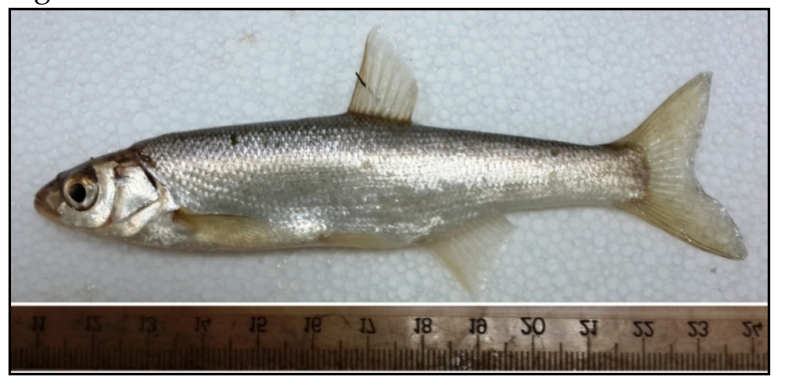

Şekil 16. Alburnus sellal Heckel, 1843

SB: 103,8 (78,5-127); SB/VY: 5,1 (4,6-5,8); SB/BB: 4,8 (4,3-5,9); BB/GÇ:2,7 (2,3-2,9); BB/İU:2,7 (2,6-2,7); İU/GÇ:0,9 (0,8-1,0); D: II/8; A: I/11-12; P: I/9; V: I/7; L. lat.: 81-90; L. trans.: 14-15/6-8; Sol. dik.: 22-29. Bu tür; 1, 2, 3, 4 ve 5 no'lu istasyonlardan yakalanmıştır.

\section{Alburnoides bipunctatus Hekel,1843}

Türkçe Adı: Noktalı inci balığ 1 İngilizce Adı: Spirlin

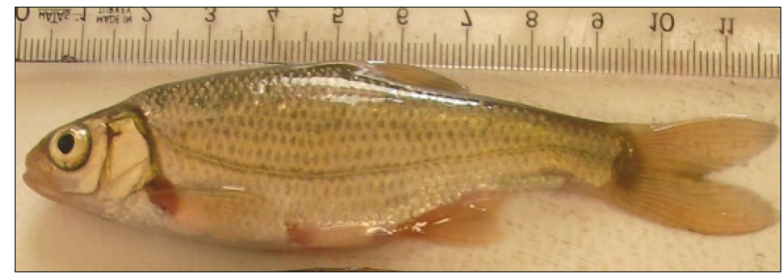

Şekil 17. Alburnoides bipunctatus Hekel,1843

SB: 93,0 (80,1-97); SB/VY: 3,7 (3,6-3,8); SB/BB: 3,8 $(3,7-3,9) ; \quad$ BB/GÇ:4,5 (4,4-4,6); BB/İU:3,4 (3,3-3,4); İU/GÇ:1,3 (1,2-1,4); D: II-III/8; A: III/11-16; L. lat.: 4452; L. trans.: 9/5. Bu tür; 2, 3, 4 ve 5 no'lu istasyonlardan yakalanmıştır.

Familya: Nemacheilidae

Oxynoemacheilus (Steindachner, 1897)

Oxynoemacheilus angorae (Steindachner, 1897)

Türkçe Adı: Çöpçü balığ1

İngilizce Adı: Angora loach 


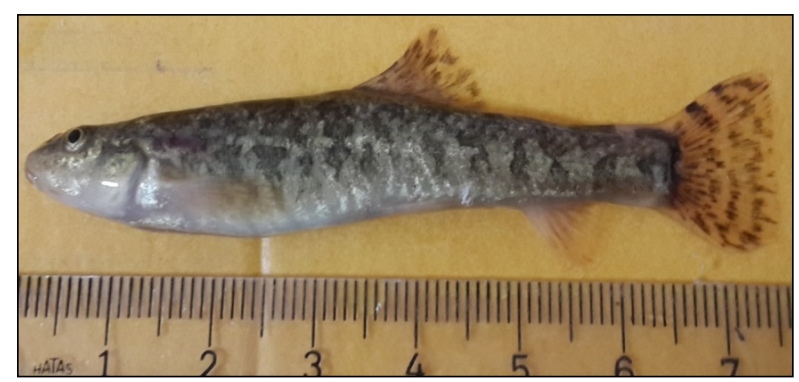

Şekil 18. Oxynoemacheilus angorae (Steindachner, 1897)

SB: 70,2 (57,3-79); SB/VY: 4,3 (4,0-4,6); SB/BB: 3,3 (3,0-3,5); BB/GÇ:10,6 (10,0-10,4); BB/İU:7,0 (6,7-7,23); İU/GÇ:1,5 (1,4-1,6); D: II/8; A: II/5; P: I/10; V: I/7; L. lat.: 46-70; L. trans.: 12-15/10-13; Sol. dik.: 14-19. Bu tür; 1 ve 2 no'lu istasyonlardan yakalanmıştır.

\section{Oxynoemacheilus bergianus (Derjavin, 1934)}

Türkçe Adı: Çöpçü balığı

İngilizce Ad1: Palaearctic loach

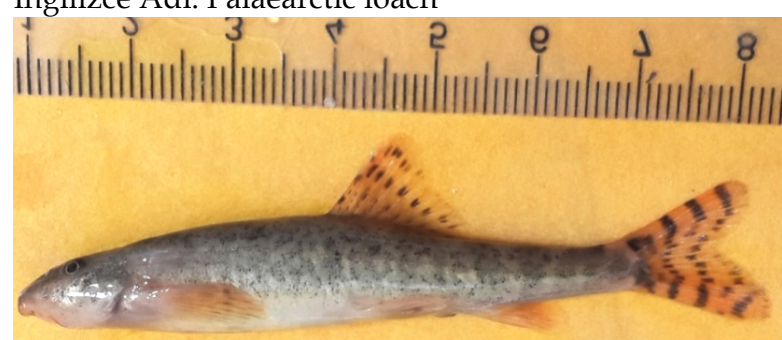

Şekil 19. Oxynoemacheilus bergianus (Derjavin, 1934)

SB: 56,5 (51-62); SB/VY: 3,2 (3,1-3,6); SB/BB: 3,0 $(2,7-3,2) ; \quad$ BB/GÇ:6,4 (6,0-6,6); BB/İU:6,0 (5,8-6,2); İU/GÇ:1,0 (0,9-1,1); D: III/8; A: II/5; P: I / 9; V: II/6; L. lat.: 42-61; L. trans.: 11-14/10-12; Sol. dik.: 13-17. Bu tür; 1 ve 2 no'lu istasyonlardan yakalanmıştır.

\section{Oxynoemacheilus Heckel, 1843}

Oxynoemacheilus tigris Heckel, 1843

Türkçe Adı: Çöpçü balığı

İngilizce Adr: Tigris loach

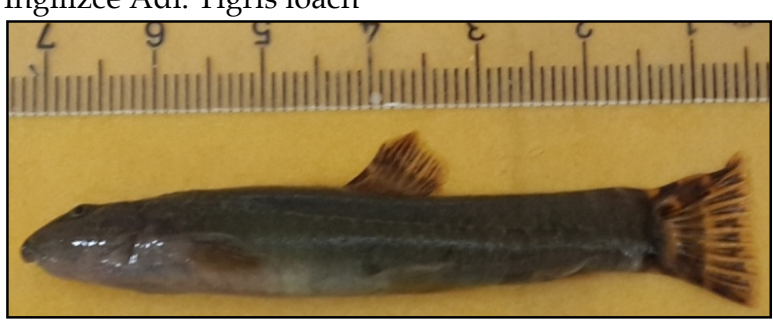

Şekil 20. Oxynoemacheilus tigris Heckel, 1843

SB: 71,2 (62-75); SB/VY: 3,9 (3,7-4,0); SB/BB: 4,3 (3,6-4,7); BB/GÇ:9,1 (8,8-9,8); BB/İU: 6,3 (6,1- 6,7); İU/GÇ:1,4 (1,0-1,5); D: II-III/7-8; A: II/5; P: I/10-11, V: I/7, L. lat.: 38-61; L. trans.: 11-13/10-12; Sol. dik.: 13-16. Bu tür; 1, 2 ve 4 no'lu istasyonlardan yakalanmıştır.

Cobitis elazigensis Coad ve Sarıeyyüpoğlu, 1988

Türkçe Adı: Taş yiyen

İngilizce Adı: Tigris spined loach

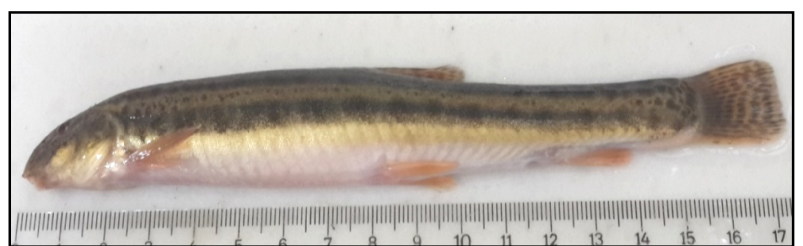

Şekil 21. Cobitis elazigensis Coad ve Sarıyyüpoğlu, 1988

SB: 111,4 (62-155); SB/VY: 7,1 (6,6-7,3); SB/BB: 5,0 $(4,8-5,9) ; \quad$ BB/GÇ: $6,9 \quad(6,0-7,8) ; \quad$ BB/İU:3,2 $\quad(2,9-3,4)$; İU/GÇ: 2,1 (2,0-2,3); D: III/6-7; A: III/5-6; P: I/7-8; V: II/5-6.Bu tür; 1 ve 2 no'lu istasyonlardan yakalanmıştır.

\section{Familya: Sisoridae}

Glyptothorax armeniacus (Berg, 1918)

Türkçe Adı: Dikenli (yapışkan) küçük yayın balığ 1 İngilizce Adı: Armenian mountain cat

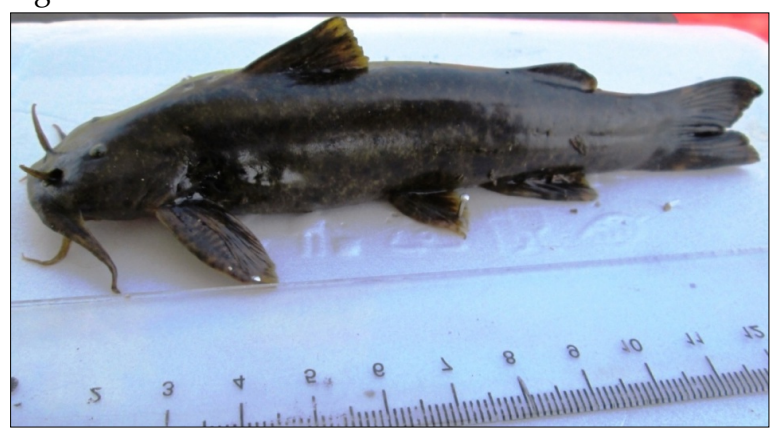

Şekil 22. Glyptothorax armeniacus (Berg, 1918)

SB: 92,2 (67,2-116,9); SB/VY: 5,7 (5,0-6,3); SB/BB: 4,1 (3,3-4,7); BB/GÇ: 10,5 (10,0-10,8); BB/İU:2,8 (2,6-2,9); İU/GÇ:3,6 (3,5-3,8); D: II/6; A: III/; P: I/9; V: I/5. Bu tür; 1,3 ve 4 no'lu istasyonlardan yakalanmıştır.

\section{Glyptothorax kurdistanicus (Berg, 1931)}

Türkçe Adı: Vantuzlu (yapışkan-dikenli) yayın balığı İngilizce Adı: Mesopotamian sucker catfish

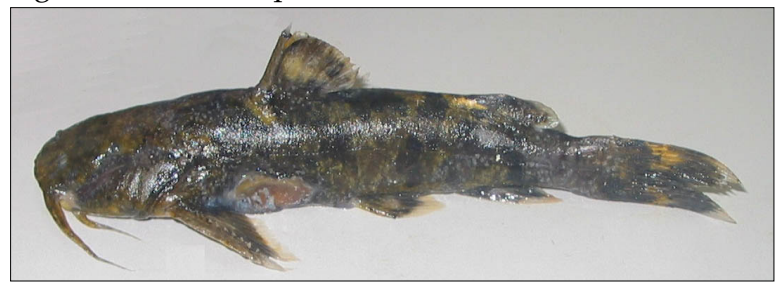

Sekil 23. Glyptothorax kurdistanicus (Berg, 1931)

SB: 86,7 (63,0-120,0); SB/VY: 5,1 (4,2-5,7); SB/BB: 4,8 (3,9-5,5); BB/GÇ: 5,9 (5,7-6,2); BB/İU:2,3 (2,2-2,4); İU/GÇ:2,5 (2,4-2,6); D: I/6; A: III/7-8; P:I/9; V: I/5. Bu tür; 1,2 ve 4 no'lu istasyonlardan yakalanmıştır.

\section{Familya: Mastacembelidae}

Mastacembelus mastacembelus (Bank ve Solander, 1794)

Türkçe Adı: Dikenli yılan balığ1

İngilizce Adı: Mesopotamian spiny eel 


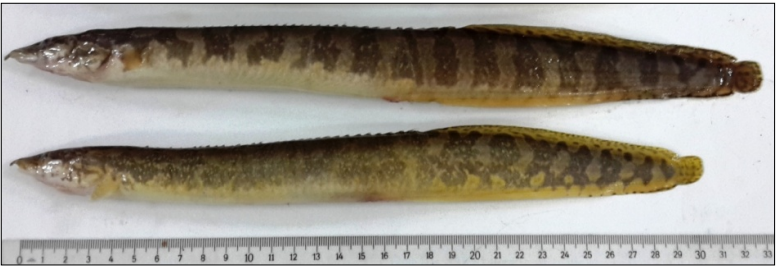

Şekil 24. Mastacembelus mastacembelus (Bank ve Solander, 1794)

SB: 415,3 (351,0-467,0); SB/VY: 11,7 (11,6-11,8); SB/BB: 6,8 (6,5-7,1); BB/GÇ: 18,9 (18,1-18,4); BB/İU:13,1 (12,5-14,1); İU/GÇ:1,4 (1,3-1,5); D: XXXIII/72-73; A: II/76-79; P: 21. Bu tür sadece 3 no'lu istasyondan yakalanmıştır

\section{Tartışma}

Çalışma alanımız Yukarı Fırat Havzası içinde yer alan ve Murat Nehri' nin önemli bir kolu olan 1890 m rakımlı Kale (Karlıva) deresi ile 1060 m. rakımlı Genç (Bingöl) demiryolu köprüsü arasında, yaklaşık $80-90 \mathrm{~km}$ uzunluğa sahip, Göynük Çayı'dır. Göynük Çayı'nın memba ile mansap arasında $830 \mathrm{~m}$.'lik rakım farkı bu suyun akış hızının çok yüksek olduğunu göstermektedir (Günek, 2006). Çalışmamızda kaydedilen A. grypus, C. regium ve $M$. mastacembalus türlerinin sadece 1 . İstasyondan kaydedilmiş olup diğer üst istasyonlarda rastlanmaması; Ulupınar et al. (2012) Murat Nehri'ndeki çalışmalarında A. grypus, C. regium ve $M$. mastacembalus türleri daha çok akarsuların göl ve göletlerin sığ alanlarını tercih ettiklerini bildirmektedirler. Çalışma alanımızın 2-3-4-5 istasyonları 1. istasyona göre eğimi daha yüksek kesimlerde kalmaktadır.

Çalışılan istasyonlardan yakalanan türlerin toplam sayı ve oranlarına bakıldığında sırasıyla; Garip Köyü (432, \%32), Ilıcalar (353, \%26), Derinçay (154, $\% 11)$, Taşliçay $(186, \% 14)$ ve Kale $(224, \% 17)$ olduğu görülmüştür. İstasyonlardaki yakalanan tür sayılarına bakıldığında ise en fazla Garip Köyü (19), Ilıcalar (13), Derinçay (12), Taşlıçay (12) ve Kale (8) tür olarak kaydedilmiştir (Tablo 2, Şekil 2-3). Garip Köyü istasyonu Murat Nehri'ne en yakın istasyondur. Görüldüğ̈ü gibi 1. istasyondan 5. istasyona doğru tür sayılarında kademeli bir azalma olmaktadır. Bu azalmaya topografik eğim, su yatağı üzerine yapılan baraj ve göletler neden olmaktadır denilebilir. Çalışma sonunda, Cyprinidae'den 14 taksona ait 1057 (\%78), diğer 4 familyaya ait 7 taksonda ise 292 (\%22) adet ve oranda örnek yakalanmıştır. Çiçek et al. (2015) yaptıkları taksonomik çalışmalarında Türkiye tatlısu balıklarının \%51,1'inin 188 tür ile Cyprinidae familyasına ait olduğunu bildirmektedirler. Bizim çalışmamızda da öne çıkan baskın türlerin Cyprinidae'ye ait türler olduğu, C. umbla, C. trutta ve Squalius semae türlerinin de Cyprinidae'ye ait baskın türler olduğu görülmüştür. Turan et al. (2017) Squalius genusuna ait yeni bir tür tanımlamaları bizim çalışmamızda kaydedilen Squalius genusuna ait türün diagnostik özelliklerinin Turan et al. (2017) ile uyum göstermesi bu örneğin Squalius semae olduğunu doğrulamaktadır. Bu çalışma ile 2017 yılına kadar Murat Nehri ve kollarında yapılan çalışmalarda Squalius cephalus olarak verilen türün $S$. semae olduğu bildirilmiştir. Bu üç türün (C. umbla, C. trutta ve Squalius semae) popülasyonlarının baskınlığı aynı havzada $C$. umbla, ve $S$. squalis'in helminth faunasına yönelik iki farklı çalışmada da hemen hemen her mevsimde yeterli sayıda örneklemenin yapılması bunu doğrulamaktadır (Koyun, 2011; 2012). Söz konusu çalışmalarda da olduğu gibi bu iki tür için (C. umbla 218 ve S. semae 116 adet) beş istasyonun tamaminda örnekleme yapılabilmiştir. Fırat ve Dicle nehir sisteminde rastlanan ve Dünya tatlısu balık literatüründe önemli yeri olan G. rufa ve C. macrostomum türlerinin (Çelik \& Güzel, 2017), özellikle Göynük Çayı'nı besleyen Ilıcalar Deresi ve buna yakın kesimlerde sayıca daha fazla olduğu kaydedilmiştir.

Kuru (2004) Türkiye iç sularında 26 familyada 236 türün bulunduğunu, yine Kuru et al. (2014) Türkiye'nin iç sularındaki balık biyoçeşitliliği ile ilgili çalışmalarında 27 familya, 92 cins ve 371 tür bildirirken, Çiçek et al. (2015) Türkiye tatlısu balıkları revizyonu çalışmalarında 2 klasis, 16 ordo, 31 familyada 10 kadar farklı tür olmaları konusunda tartışmalı taksonlar dışında 368 türün olduğuna işaret etmektedirler. Bu bildirilen familyalardan da en fazla 188 tür ve \%51,1 oranla Cyprinidae olduğu bildirilmektedir. Bizim çalışmamızda da Türkiye geneline uyumlu bir sonuçla baskın familyanın 14 tür ve \%78 oranla Cyprinidae olduğu bildirilmiştir.

Firat Havzasında ilk fauna araştırması Kuru (1971) tarafından yapılmış ve 9 familyaya ait 32 tür kaydedilmiştir. Ancak Kuru (1971)'nun tespit ettiği türlerden bazılarının daha sonra bu bölgede yapılan çalışmalarda rastlanmadığı görülmektedir. Keban Baraj Gölünde; Ekingen \& Sarıyyüpoğlu (1981)'nun Keban barajını besleyen Murat Nehri ve kollarında yaptığ araştırmada 6 familyaya ait 22 tür kaydı verilmektedir. Söz konusu çalışmada verilen kayıtlardaki Carassius cinsine ait $C$. carassius ve $C$. auratus türlerine Göynük Çayı ve kollarında rastlanmamıştır. Keban Barajı'nın balıklandırma çalışmalarıyla ortama bırakılan Carassius cinsine ait bu iki tür Türkiye tatlı sularına bir şekilde sonradan geldiği bilinen egzotik türlerdir (Şaşı \& Balık, 2003; Uğurlu, 2006). Ancak bu durum daha sonra yapılacak çalışmalarda bu türlere rastlanmayacağ anlamına da gelmemektedir. Çünkü bilinçsiz balıklandırma ile sıcaklığa, kirliliğe ve düşük oksijen konsantrasyonuna karşı toleransı oldukça yüksek olan bu istilacı cinsin üyeleri akarsularda bile yaşama şansı bulabilmektedirler (Özcan, 2007; Yazıcıoğlu et al., 2013).

Kuru (1971)'nun Fırat nehir sisteminde yapmış olduğu çalışmada bildirdiği türler ile bizim çalışmamızda kaydedilen türler arasında uyum görülmektedir. Birecikligil \& Çiçek (2010) Fırat Nehir havzasında 39 tür balığın yaşadığını bildirilmektedirler. Bizim çalışmamızda yakalanan 21 balık türü ile Fırat nehir havzasında bulunan türlerin yaklaşık \%54'ünün örtüştüğü görülmektedir. Ekingen \& Sarıeyyüpoğlu (1981)'nun Keban Baraj Gölündeki çalışması ile bizim çalışmamız kıyaslandığında farklı olan türlerin Barbus cinsine ait iki tür Barbus plebejus escherichi ve Barbus capito pectoralis olduğu görülmüştür. Geldiay \& Balık (2007)'a göre bu iki türden B. plebejus escherichi'nin doğal yayılış alanının Ege ve Batı Anadolu iç suları olduğu ve Ekingen \& Sar1eyyüpoğlu (1981)'nun çalışmasında bu türe ait verilerin Güney ve Güney Doğu Anadolu Bölgesi olarak verilmesi bir hata olarak görülmektedir (Yıldırım et al., 2015). Söz konusu çalışmada verilen bu iki türe bizim çalışmamızda 
rastlanmadığı gibi Dicle-Firat nehir sisteminde yapılan diğer faunistik çalışmalarda da rastlanmamıştır (Birecikligil \& Çiçek, 2010; Çiçek et al., 2015). Muhtemelen yapılan bir hatadan dolayı bildirilen türün Barbus lacerta olabileceği daha sonra yapilan çalışmalarda görülmektedir (Yıldırım et al., 2015).

Tablo 2'de de verildiği gibi bu çalışmada kaydedilen 5 familyaya ait 21 taksondan 7'si; C. umbla, C. trutta, S. semae, A. marmid, B. lacerta, A. sellal ve G. rufa beş istasyonun tamaminda, A. bipunctatus'a ise Garip Köyü haricinde diğer istasyonların tamamında rastlanmıştır. G. armeniacus ve G. kurdistanicus türleri Kale ve Ilıcalar dişındaki istasyonlardan elde edilebilmiştir. C. macrostomum, C. regium ve O. bergianus türleri ise sadece iki istasyondan (Garip Köyü-Ilıcalar) toplanabilmiştir. Araştırmamızdaki balık türlerinden beşi sadece birer istasyondan, A. grypus, L. xanthopterus ve $L$. esocinus Derinçay'dan, $C$. carpio ve $M$. mastacembelus ise Garip istasyonundan kaydedilebilmiştir.

Bizim çalışmamıza en yakın ve güncel olan çalışma Yıldırım et al. (2015) tarafından Yukarı Fırat havzasında yapılmıştır. Çalışmada bizim çalışmamızdan farklı olarak (Salmonidae, Bagridae) familyaları verilmektedir. Salmonidae'ye ait verilen iki türden (Oncorhynchus mykiss, Salmo macrostigma) $O$. mykiss doğal olmayıp Keban Baraj Gölündeki yetiştirme ortamlarında bulunmaktadır. Bagridae'ye ait Mystus pelusius, Göynük Çayı'nın bağlantılı olduğu Murat Nehri'nden kayıt bulunmaktadır (Ulupınar et al., 2010). Ancak bizim çalışmamızda rastlanmamış olmasını Göynük Çayı'nın debisinin yüksek ve dere yatağının çakıllı olması gibi nedenlerden dolayı M. pelusius'un suyun hızlı akan ve zemini çakıllı olan bu kesimlere girmediği söylenebilir. (Geldiay \& Balık, 2007)'a göre M. pelusius'un daha çok durgun ve yavaş akan dere yataklarında bulunduğu bildirilmektedir. Luciobarbus subquincunciatus (Komando balığı) türü için (Coad, 2009) habitatlarında neredeyse yok olmakta olduğuna dikkat çekmektedir. IUCN verilerine göre de critically endangered (nesli kritik tehlike altında) olduğu bildirilmektedir.

Sonuç olarak Göynük Çayı (Bingöl) balık faunasının tespitine yönelik bu çalışma ile Doğu Anadolu Bölgesi ve dolayısıyla ülkemiz su ürünleri potansiyelinin belirlenmesi ve biyoçeşitliliğin tespiti gibi konular için önemli bir katkı sağlayacağı ve ileride yapılacak çalışmalara da yön vereceği düşünülmektedir.

\section{Kaynaklar}

Aşık, Y. (2016). Barajların kontrolü ve denetiminin önemi. Gümüşhane Üniversitesi Fen Bilimleri Enstitüsü Dergisi, 6 (1): 33-40.

Birecikligil, S., \& Çiçek, E. (2010). Gaziantep ili sınırları içindeki Fırat ve Asi Havzası akarsuları balık faunası. Biyoloji Bilimleri Araştırma Dergisi 3 (1): 107-115

Çelik, P., \& Güzel E. (2017). Faklı su sıcaklıklarının Beni balığı (Cyprinion macrostomus) yavrularının büyümesi üzerine etkisi. Memba Su Ürünleri Fakültesi Dergisi, 3 (1-2): 1-7.

Çiçek, E., Birecikligil, S. S., \& Fricke, R. (2015). Freshwater fishes of Turkey: A revised and updated annotated checklist. Biharean Biologist, 9 (2): 141-157.

Coad B. W. (2009). Threatened fishes of the world: Luciobarbus subquincunciatus (Günther, 1868) (Cyprinidae). Environmental Biology of Fishes, 86: 323.
Çoban, M. Z., Gündüz, F., Yüksel, F., Demirol, F., Yıldırım, T., \& Kurtoğlu, M. (2013). Uzunçayır Baraj Gölü (Tunceli) balık faunası. Yunus Araştırma Bülteni, 2: 35-44.

Ekingen G., \& Sarıyyüpoğlu M. (1981). Keban Baraj Gölü balıkları. Frrat Üniversitesi Veteriner Fakültesi Dergisi, 4 (1-2): 7-22.

Ekingen, G., \& Erbucan, S. (1993). Elazı̆̆ yöresi balıkları tanı anahtarı. F.Ü.Su Ürünleri Fakültesi Yayınları, 3: 1- 18.

Enerji Atlasi: http://www.enerjiatlasi.com/akarsular/goynukcayi.html

Erk'akan, F., Atalay-Ekmekçi, F. G., \& Nalbant, T. T. (1999). A review of Genus Cobitis in Turkey (Pisces:Ostariophysi:Cobitidae). Hydrobiologia, 403, 13-26.

FishBase. (2018). Catalogue of Life: Indexing the world's known species “Froese R. ve Pauly D. (eds) (2018)", 28th March, 2018.

Geldiay, R., \& Balık, S. (2007). Türkiye tatlısu balıkları (V. Baskı). Ege Üniv. Su Ürünleri Fakültesi Yayınları, No: 46, İzmir, 644 s.

Günek, H. (2006). Murat Nehri havzasının (Fırat) su potansiyeli ve değerlendirilmesi (hydropower potential and its assessing in Murat River Basin). Eastern Geographical Review, 16: 141-164.

Kaya, C., \& Turan, D., Ünlü, E. (2016). The latest status and distribution of fishes in upper Tigris River and two new records for Turkish freshwaters. Turkish Journal of Fisheries and Aquatic Sciences, 16: $545-562$.

Koyun, M. (2011). Occurrence of Monogeneans on some cyprinid fishes from Murat River in Turkey. African Journal of Biotechnology, 10 (79):18285-18293.

Koyun, M. (2012). The occurrence of parasitic helminths of Capoeta umbla in relation to seasons, host size, age and gender of the host in Murat River, Turkey. Journal of Animal and Veterinary Advances, 11 (5):609-614.

Kuru, M. (1971). The freshwater fish fauna of Eastern Anatolia. İstanbul Üniversitesi Fen Fakültesi Mecmuası, Ser. B, 36: 137-147.

Kuru, M. (1975). Dicle-Fırat Kura-Aras Van Gölü ve Karadeniz Havzası tatlı sularında yaşayan balıkların (Pisces) sistematik ve zoocoğrafik yönden incelenmesi. Doçentlik tezi Atatürk Üniversitesi Erzurum, $186 \mathrm{~s}$.

Kuru, M. (1980). Türkiye Tatlısu Balıkları Kataloğu. Hacettepe Üniversitesi Fen Fakültesi Yayınları yardımcı kitaplar dizisi, 1, 73 pp.

Kuru, M. (2004). Türkiye içsu balıklarının son sistematik durumu. G.Ü, Gazi Eğitim Fakültesi Dergisi, 24 (3): 1-21.

Kuru, M., Yerli, S. V., Mangit, F., Ünlü, E., \& Alp, A. (2014). Fish biodiversity inland waters of Turkey. Journal of Academic Documents for Fisheries and Aquaculture, 3: 93-120.

Lagler, K., Bardach, J. E., Miller, R., \& Passino D. R. M. (1977) Ichthyology. John Wiley, New York. US. 1977. 506, p.597.

Özcan, G. (2007). Distribution of the non-native fish species, pumpkinseed Lepomis gibbosus (Linnaeus, 1758), in Turkey. Aquat Invasions, 2: 146-148.

Saşı, H., \& Balık, S. (2003). The distribution of three exotic fishes in Anatolia. Turkish Journal of Zoology, 27: 319-322.

Scott, W. B., \& Crossman E. J. (1979). Freshwater Fishes of Canada. The Bryant Press Limited, Ottawa, Canada, pp. 767-774.

Sönmez, M. E. (2012). Barajların mekân üzerindeki olumsuz etkileri ve türkiye'den örnekler. Gaziantep Üniversitesi Sosyal Bilimler Dergisi, 11 (1):213-231

Stout, C. C., Tan, M., Lemmon, A. R., Lemmon, E. M., \& Armbruster, J. W. (2016). Resolving Cypriniformes relationships using an anchored enrichment approach. BMC Evolutionary Biology, 16 (244): 2-13. DOI 10.1186/s12862-016-0819-5

Turan, D., Kottelat, M., \& Bayçelebi, E. (2017). Squalius semae, a new species of chub from the Euphrates River, Eastern Anatolia (Teleostei: Cyprinidae). Zoology in the Middle East, 63: 1, 33-42. https://doi.org/10.1080/09397140.2017.1290761

Uğurlu, S. (2006). Samsun ili tatlısu balık faunasının belirlenmesi. Samsun Ondokuz Mayıs Üniversitesi Fen Bilimleri Enstitüsü Biyoloji Anabilim Dalı, Dok. Tezi, 147 s.

Ulupınar, M., Koyun, M., Yıldırım T., Şen Özdemir N., \& Kırıcı, M (2012). Murat Nehri balık ve zooplankton faunasının tespiti. Bingöl 
Üniversitesi Bilimsel Araştırma Projeleri, Proje No: BÜBAP/2010/18, $113 \mathrm{~s}$.

Vatandoust, S., Abdoli, A., Anvarifar, H. \& Mousavi-Sabet, H. (2014). Morphometric and meristic characteristics and morphological fario (Pisces: Salmonidae) along the southern Caspian Sea basin. European Journal of Zoological Research, 3 (2): 56-65.

Yazıcığlu, O., Yılmaz, S., Yazıcı, R., \& Polat, N. (2013). Ladik Gölü (Samsun, Türkiye)'nde yaşayan Havuz Balı̆ı̆, Carassius gibelio (Bloch, 1782)'nun kondisyon faktörü, boy-ağırlık ve boy-boy İlişkileri. Karadeniz Fen Bilimleri Dergisi, 3 (9):72-80.

Yıldırım T., Şen D., Eroğlu M., Çoban M. Z., Demirol, F., Gündüz F., Arca S., Demir T., Gürçay S., Uslu, A. A., \& Canpolat, İ. (2015). Keban Baraj Gölü balık faunası, Elazı ğ - Türkiye. Firat Üniversitesi Fen Bilimleri Dergisi 27 (1): 57-69. 